\title{
Bacterial nitrogen fixation in sand bioreactors treating winery wastewater with a high carbon to nitrogen ratio
}

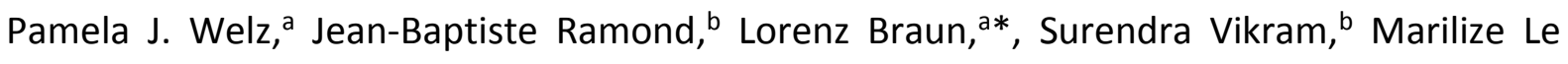
Roes-Hilla

${ }^{a}$ Biocatalysis and Technical Biology Research group, Institute for Medical and Microbial Biotechnology, Cape Peninsula University of Technology, Cape Town, South Africa; ${ }^{b}$ Centre for Microbial Ecology and Genomics, Department of Genetics, University of Pretoria, Pretoria, South Africa

*Present address: Nurtingen College for Economics and the Environment, Germany

\section{Highlights}

- Sand bioreactors remediated synthetic winery wastewater with a carbon to nitrogen ratio of 193:1.

- The number of culture-able nitrogen-fixing bacteria increased at the surface of sand bioreactors.

- There was a shift in the nitrogen-fixing bacterial communities at the surface of sand bioreactors.

- Nitrogen-fixation may increase the performance of sand bioreactors treating winery wastewater.

\begin{abstract}
Heterotrophic bacteria proliferate in organic-rich environments and systems containing sufficient essential nutrients. Nitrogen, phosphorus and potassium are the nutrients required in the highest concentrations. The ratio of carbon to nitrogen is an important consideration for wastewater bioremediation because insufficient nitrogen may result in decreased treatment efficiency. It has been shown that during the treatment of effluent from the pulp and paper industry, bacterial nitrogen fixation can supplement the nitrogen requirements of suspended growth systems. This study was conducted using physicochemical analyses and culture-dependent and -independent techniques to ascertain whether nitrogen-fixing bacteria were selected in biological sand filters used to treat synthetic winery wastewater with a high carbon to nitrogen ratio (193:1). The systems performed well, with the influent COD of $1351 \mathrm{mg} / \mathrm{L}$ being reduced by $84-89 \%$. It was shown that the nitrogen fixing bacterial population was influenced by the presence of synthetic winery effluent in the surface layers of the biological sand filters, but not in the deeper layers. It was hypothesised that this was due to the greater availability of atmospheric nitrogen at the surface. The numbers of culture-able nitrogen-fixing bacteria, including presumptive Azotobacter spp. exhibited 1-2 log increases at the surface. The results of this study confirm that nitrogen fixation is an important mechanism to be considered during treatment of high carbon to nitrogen wastewater. If biological treatment systems can be operated to stimulate this phenomenon, it may obviate the need for nitrogen addition.
\end{abstract}


Keywords: Bacterial nitrogen fixation, high C:N wastewater, winery wastewater, biological sand filters

\author{
Abbreviations \\ BN: $\quad$ Basal nutrients \\ BSF: $\quad$ Biological sand filter \\ NF: $\quad$ Nitrogen fixation \\ NFB: $\quad$ Nitrogen-fixing bacteria \\ SWW: $\quad$ Synthetic winery wastewater
}

\title{
1. Introduction
}

Nitrification, denitrification and nitrogen fixation (NF) are the main processes responsible for the biogeochemical cycling of N, represented by the N cycle (Ray et al., 2014). NF is the process whereby $\mathrm{N}_{2}$ gas is converted into ammonia by heterotrophic bacteria or photosynthetic $\mathrm{N}$-fixing bacteria (NFB) and the reaction is catalysed by an intracellular nitrogenase enzyme system (Olivares et al., 2013). In soil environments, particularly in plant rhizospheres, NFB naturally supply $\mathrm{N}$ for the growth of crops and indigenous plants (Barua et al., 2012; De Salamone et al., 2012). Bioaugmentation of N-deficient soils with NFB can increase crop yield, although negative effects have also been demonstrated (Barua et al., 2012; De Salamone et al., 2012). N is also an essential nutrient for all bacteria, and consequently high concentrations of organics in the soil environment (e.g. from petroleum oil or olive mill waste) have been shown to result in the selection of NFB which provide N for the carbon (C)-degrading microbial populations (Balis et al., 1996; Chronopolou et al., 2013).

$\mathrm{N}$ is also important in biological wastewater treatment plants, where the general premise is that unless exogenous $\mathrm{N}$ is added, performance decreases when the influent $\mathrm{N}$ to $\mathrm{C}$ ratio falls below 0.05 (Sakar et al., 2016; Tchobanoglous et al., 2003). However, it has been demonstrated that in some instances, natural NF increases the amount of $\mathrm{N}$ available in systems treating high $\mathrm{C}: \mathrm{N}$ wastewater. It has been suggested that in these circumstances, exogenous N should not be added as it suppresses NF (Clark et al., 1999; Dennis et al., 2004; Kargi and Özmıhçı, 2004).

A number of publications have described the use of $\mathrm{N}$-fixing systems for the successful treatment of pulp and paper mill effluent in suspended growth laboratory-scale (e.g. Dennis et al., 2004; Kargi and Özmıhçı, 2004) and full-scale systems (e.g. Clark et al., 1999; Dennis et al., 2004). For example, approximately $600 \mathrm{~kg} \mathrm{~N} /$ day was fixed in an aerated stabilisation basin with a capacity of $120000 \mathrm{~m}^{3}$ and hydraulic retention time of 1.2 days when treating kraft mill wastewater (Clark et al., 1999). More recently, it was shown that NF occurred at the anode of a bioelectrical system fed with glucose (Wong et al., 2014). Apart from the obvious cost and labour savings, a major advantage of these self-regulating systems over 
those where exogenous $\mathrm{N}$ is added, is that the final effluent $\mathrm{N}$ concentrations are low and stable (Clark et al., 1999; Pratt et al., 2007). In addition, granular morphology, sludge settleability, and dewater-ability may be improved, as demonstrated in laboratory scale sequencing batch reactors (Clark et al., 1999; Pratt et al., 2007). Despite the fact that nitrogenases are sensitive to oxygen, it has been established that high dissolved oxygen concentrations created via aeration do not negatively affect the functional NF population (Pratt et al., 2007; Slade et al., 2003). This is probably because of well described intrinsic intracellular and extracellular mechanisms which protect the enzymes from oxygen exposure (Pratt et al., 2007; Slade et al., 2003).

Bioaugmentation is the practice of supplementing an environment with exogenous microorganisms in order to stimulate bioremediation. In the case of biological wastewater treatment systems, bioaugmentation is controversial (Gentry et al., 2004). Not only is there a cost consideration, but the introduced organisms may not be suited to the prevailing conditions and will be competitively eliminated by the existing flora (Gentry et al., 2004). However, in laboratory-scale experiments, in which reactors are not exposed to an environmental microbial pool, inoculation with known diazotrophs is an option. For example, in flask experiments, the treatment of $\mathrm{N}$-deficient wastewater was improved by the addition of Azotobater vinelandii to activated sludge (Kargi and Özmıhçı, 2004), and inoculation with reference strains of Azotobacter spp. resulted in the reduction of the polyphenolic content of olive mill wastewater (Aquilanti et al., 2014). The latter finding was supported by Piperidou et al. (2000), who found that inoculation of a pilot-scale fed-batch reactor with $A$. vinelandii resulted in the elimination of potentially phytotoxic organics from olive mill wastewater.

In a previous study, the performance of two biological sand filters (BSFs) treating high COD:N wastewater were compared. Both systems were used to treat synthetic wastewater with the same composition, but in one replicate, nutrients were added to provide an 'ideal' COD:N:P ratio. During these experiments, satisfactory COD removal was achieved in the nutrient-deprived system (approx. 80\% removal with an influent COD of $7587 \mathrm{mg} / \mathrm{L}$ ). However, the COD removal rate and nitrate reductase activity was significantly higher in the nutrient-supplemented system (Rodriguez-Caballaro et al., 2012). It was hypothesised that the organic substrate was being utilised as an electron donor for heterotrophic denitrification. In the BSF that was not nutrient-supplemented, a thick layer of slime developed on the surface. A Gram stain and culture of the layer revealed an abundance of Gram negative bacteria, with the distinctive microscopic and colonial morphology of Azotobacter spp. Identity was confirmed by sequencing $16 \mathrm{~S}$ rRNA gene amplicons as Azotobacter chroococcum (J.B. Ramond, unpublished data).

Azotobacter spp. are diazotrophs that fix nitrogen at high rates and are known to produce copious amounts of extracellular polysaccharide slime to protect the sensitive nitrogenase enzyme system from oxygen toxicity (Pratt et al., 2007). It was speculated that $\mathrm{N}$ limitation 
led to the natural selection of Azotobacter spp. over time. Using culture-dependent methods, it was determined that there were significantly lower numbers of Azotobacter spp. in the nutrient-supplemented BSFs (P.J. Welz, unpublished data).

In a separate study, the nifH gene was used as a marker to monitor the changes in the NFB population in BSF systems exposed to a phenolic cocktail with a final COD concentration of $5842 \mathrm{mg} / \mathrm{L}$ and a high C:N ratio (100:0.1) (Ramond et al., 2013). Analysis of terminal restriction fragment length polymorphism (T-RFLP) and denaturing gradient gel electrophoresis (DGGE) results showed that there was a significant structural change in the NFB population after exposure to the phenolic cocktail, with the selection of various Azotobacter spp. and Beijerinckia indica. In terms of the NFB populations, these results differed from those previously found with kraft-mill wastewater, and in a bioelectrochemical system, where coliforms and Clostridium spp., respectively, were thought to be responsible for NF (Gauthier et al., 2000; Knowles et al., 1974; Wong et al., 2014).

In light of these findings, a study was designed to specifically focus on the NFB population in BSFs treating high $\mathrm{C}: \mathrm{N}$ wastewater. The main aim of the study was to ascertain whether there would be a qualitative and/or quantitative adjustment of the nitrogen-fixing bacterial population in sand bioreactors in response to exposure to synthetic winery wastewater (SWW). It was hypothesised that there would be a structural and functional adaptation of this population. Physicochemical and microbiological results of replicate samples from BSF systems were compared with control replicate samples before and after addition of SWW over the period of 3 months. Changes in the community structure of bacteria harbouring the nifH gene were analysed using T-RFLP, next generation sequencing (NGS), and culture-based enumeration techniques.

\section{Materials and Methods}

\subsection{Set-up and operation of biological sand filters}

Three identical BSFs were used in this study, one control (designated C) and two experimental systems (designated 1 and 2). The systems were installed in an outdoor, undercover environment. The BSFs consisted of sturdy polyethylene containers $(1.73 \mathrm{~m}$ in length, $1.06 \mathrm{~m}$ in width) containing sand to a depth of $0.3 \mathrm{~m}$, with a total volume of 0.502 $\mathrm{m}^{3}$, and void volume of $0.13 \mathrm{~m}^{3}$. The sand was a mix from two quarry sites, with a final density of $1.60 \pm 0.03 \mathrm{~kg} / \mathrm{L}$ and porosity of $258 \pm 22 \mathrm{~L} / \mathrm{m}^{3}$ sand (measured before feeding/amendment). The hydraulic conductivity of $0.15 \mathrm{~mm} / \mathrm{sec}$ (determined by the constant head method) ensured that the systems were capable of draining rapidly, so that the average saturated permeation rate of effluent outflow from the systems before the start of the experiment was $21.1 \pm 2.7 \mathrm{~L} / \mathrm{hr}^{3} \mathrm{~m}^{3}$ sand $^{-1}$. The physicochemical characteristics of the sand are given in Table 1. A more detailed explanation of the set-up and operation is provided in Welz et al. (2014a) and Welz et al. (2014b). 
In order to rapidly establish an appropriate microbial population, the BSFs were preinoculated with sand taken from other systems previously amended with winery wastewater and/or SWW (1 kg mixed sand suspended in $10 \mathrm{~L}$ tap water and spread evenly over the surface). The influent was pumped via drip irrigation onto the surface of the sand at the inlet, at a pumping rate of $0.67 \mathrm{~L} / \mathrm{min}$. The outlets were located on the opposite (longitudinal) side to the inlet, and at the bottom of the polyethylene containers. The flow of wastewater thus took place both longitudinally and vertically towards the outlet.

Table 1: Physicochemical characteristics of the sand used in the biological sand filters

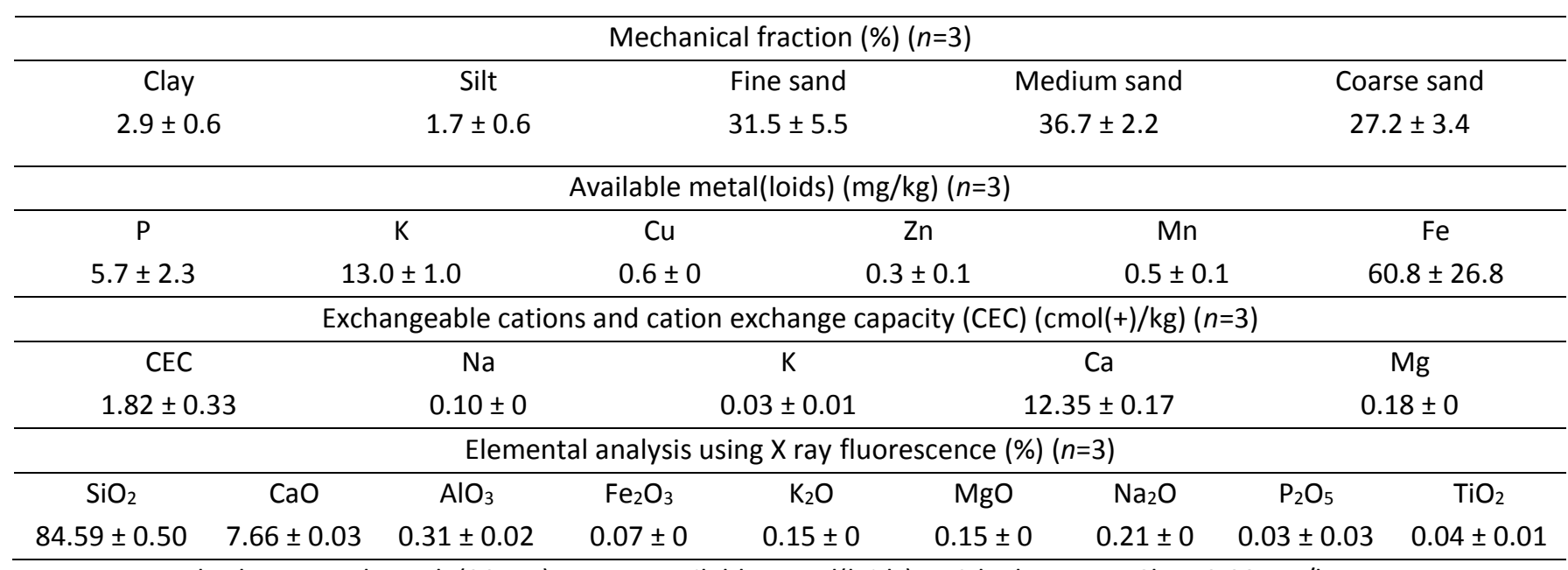

For methods, see Welz et al. (2014a) Available metal(loids) B, Cd, Pb, As, Hg, Sb: $<0.08 \mathrm{mg} / \mathrm{kg}$

The BSFs were operated in batch mode, with alternating periods of flooding and drainage: prior to feeding or amendment, the outlets were plugged, the systems were then fed and/or amended, and after $48 \mathrm{hrs}$, the outlets were unplugged and the systems were allowed to drain spontaneously (Table 2). The use of batch mode has been shown to minimise clogging in comparison to continuous mode (Knowles et al., 2010). The feeding/amendment procedure was performed twice weekly. Initially, the BSFs were fed with a dilute solution of basal nutrients (BN) consisting of $1 \mathrm{~g}$ yeast extract (Biolab, Midrand, South Africa) and $1.0 \mathrm{~g}$ $D(+)$ glucose (Merck, Darmstadt, Germany) dissolved in $40 \mathrm{~L}$ tap water for a period of three months. This was in order to allow the microbial communities within the BSFs to equilibrate through acclimation (Ramond et al., 2012). Subsequently, for a further 3 months, the BSFs were fed with BN as previously, but the experimental BSFs (1 and 2) were also amended with SWW (Table 2). To mimic authentic winery wastewater, the organic composition of the SWW consisted of readily biodegradable substrate [glucose (COD $400 \mathrm{mg} / \mathrm{L}$ ), and ethanol (COD $500 \mathrm{mg} / \mathrm{L}$ )], as well as more recalcitrant phenolic substrates, namely, gallic acid and vanillin (COD $50 \mathrm{mg} / \mathrm{L}$ each). The SWW was formulated on known characteristic of authentic winery wastewater (Malandra et al., 2003; Welz et al., 2016). 
Table 2: Feeding/amendment of biological sand filters during the equilibration (month 1-3) and experimental period (month 4-6)

\begin{tabular}{lcccc} 
& \multicolumn{2}{c}{ Month 1-3 } & \multicolumn{2}{c}{ Month 4-6 } \\
\hline & $\mathrm{C}$ & 1,2 & $\mathrm{C}$ & 1,2 \\
Influent volume (L) & 40 & 40 & 40 & 40 \\
Feeding & $\mathrm{BN}$ & $\mathrm{BN}$ & $\mathrm{BN}$ & $\mathrm{BN}$ \\
Amendment & - & - & - & $\mathrm{SWW}$ \\
Influent COD (mg/L) & 27 & 27 & 27 & 1027 \\
OLR (mgCOD/m sand.day $^{-1}$ ) & 15 & 15 & 15 & 585 \\
COD:N:P ratio & $36: 7: 1$ & $36: 7: 1$ & $36: 7: 1$ & $1351: 7: 1$ \\
\hline BN: basal nutrients & SWW: synthetic winery wastewater & OLR: organic loading rate
\end{tabular}

\subsection{Effluent, pore water and sand sample collection}

It has previously been well established that the BSF systems are effective for the treatment of SWW (e.g. Welz et al., 2014a, 2014b) so monthly effluent samples were taken to confirm that the systems were functioning as expected. Effluent samples $(1 \mathrm{~L})$ were taken 10 minutes after unplugging the systems from the outlet of each BSF at baseline, 1 and 2 months after the start of amendment with SWW, and at the final sampling instance. Pore water and sand samples were taken $24 \mathrm{hrs}$ after feeding/amendment, while the systems were plugged. The pore water, extracted from the pore spaces of the sand substratum, represented the bulk water of the system. However, only planktonic microbial communities are present in the pore water, so extraction of the functional biofilm-associated communities from sand samples was essential for this study. Sampling of pore water and sand was performed twice: after the three month equilibration period (baseline samples) and experimental period (final samples).

For each BSF, 9 core sand samples were extracted from pre-designated sites $0.5 \mathrm{~m}$ from the inlet/outlets, and $0.14 \mathrm{~m}$ from the sides of the tanks using a randomised block design grid. At each sampling instance (baseline and final), perspex corers (internal diameter of $2.5 \mathrm{~cm}$ ) were used to extract 18 core sand samples from each BSF. Nine samples were taken from the surface niche $(0$ to $-5 \mathrm{~cm})$ and 9 from the deep niche $(-20$ to $-25 \mathrm{~cm})$ of each BSF. Triplicates from pre-selected sites that were the same for each BSF were pooled and thoroughly mixed to form composites, so that there were 3 replicates for each niche from each BSF at each sampling instance (Schank and Koehnle, 2009).

Six polyvinyl chloride pipes were positioned in-situ in pairs (surface/deep) in each BSF at the same spatial location. Three pipes were used to collect surface pore water samples and additional three pipes to collect deep pore water samples. The pipes were equally spaced across the width of the systems and located longitudinally $0.865 \mathrm{~m}$ from the inlet and outlet. Only the pore water (no sand particles) permeated through the perforations to fill the pipe cores. Devices consisting of tubing attached to syringes were used to extract the samples from the pipes. Before sampling, all of the existing wastewater in the pipes was extracted and discarded to ensure that the replicates were a true reflection of the pore 
water between the sand. The pipes were perforated to allow wastewater ingress at the same depths from which the sand samples were taken. They were perforated between 0 and $-5 \mathrm{~cm}$ (surface samples) or between -20 and $-25 \mathrm{~cm}$ (deep samples).

\subsection{Characterisation of pore water samples}

All pore water samples were analysed immediately after collection. All analyses were performed spectrophotometrically using a Merck Spectroquant ${ }^{\circledR}$ Pharo instrument and Merck Spectroquant ${ }^{\circledR}$ reagents, together with all relevant controls and standards according to the manufacturers' instructions.

The concentrations of COD (cell test: cat no 1.14540 and 1.14541), nitrate (reagent kit: cat no 1.09713), nitrite (cell test: 1.14547), and ammonia (reagent kit: 1.00683) were determined in all samples. In addition, the concentration of total $\mathrm{N}$ (cell test: cat no 1.14537) was determined in the final samples.

\subsection{Culture-dependent quantification of nitrogen fixing bacteria}

To release the bacteria attached to the sand particles, $10 \mathrm{~g}$ of each sand sample was added to $95 \mathrm{ml}$ of sterile Ringers solution and $10 \mathrm{~g}$ of $3 \mathrm{~mm}$ glass beads in $100 \mathrm{ml}$ Erlenmeyer flasks ( $10^{-1}$ dilution). The flasks were placed on a rotary shaker at $200 \mathrm{rpm}$ for 30 minutes, after which 10-fold serial dilutions were made in Ringers solution. According to Zuberer et al. (1994), this type of method is effective for releasing bacteria from samples other than peat or clay. $0.1 \mathrm{ml}$ of each dilution was added to, and spread over the surface of petri dishes containing $\mathrm{N}$-deficient combined carbohydrate medium (Rennie, 1981) or Azotobacter medium (Brown et al., 1962), after which the plates were incubated aerobically at room temperature for 10 days. All procedures were performed aseptically and in duplicate.

\subsection{Genomic analysis of the nitrogen fixing bacterial community}

\subsubsection{Metagenomic DNA extraction}

Total metagenomic DNA was extracted from $0.5 \mathrm{~g}$ sand samples (wet weight) using the Powersoil DNA isolation kit according to the manufacturers' instructions (MoBio laboratories, Carlsbad, USA). The first step in this method relies on a bead beating method to release the associated bacteria from the sand particles.

\subsubsection{PCR amplification and purification}

The NFB community was assessed using the nifH gene as a marker. The gene sequences were amplified by polymerase chain reaction (PCR) using the PolF and PolR primer set (23). PCR reactions were carried out in $50 \mu \mathrm{l}$ reaction volumes, each containing $1 \mathrm{X}$ DreamTaq PCR Mastermix (Fermentas, Burlington, Canada), $0.25 \mu \mathrm{M}$ of each primer, $0.1 \%(\mathrm{w} / \mathrm{v})$ molecular grade bovine serum albumin (Fermentas) and between 10 to $20 \mathrm{ng}$ of metagenomic DNA. 
Amplification was carried out in a Touchgene gradient thermal cycler (Techne, Minneapolis, USA) using the PCR conditions described by Poly et al. (2001). All PCR products were visualised on $2 \%(\mathrm{w} / \mathrm{v})$ agarose gel and the amount of amplified product present in each sample was quantified using a Jenway Genova (Bibby Scientific, Staffordshire, England) Nanodrop spectrophotometer.

\subsubsection{Diazotrophic bacterial community fingerprinting using terminal restriction fragment length polymorphism}

To perform T-RFLP analyses, the PolF primer was labelled with 6-carboxy fluorescein (FAM) at the 5 '-end. The purified PCR products were quantified by Nanodrop spectrophotometry and approx. $100 \mathrm{ng}$ was digested with the restriction enzyme Alul (Sigma-Aldrich, St Louis, USA) for 3 hours at $37^{\circ} \mathrm{C}$. Thereafter the restriction enzymes were inactivated by heating at $80^{\circ} \mathrm{C}$ for 10 minutes and purified using the NucleoSpin ${ }^{\circledR}$ gel and PCR clean-up kit (MacheryNagel, Duren, Germany).

Digested samples were analysed at the Central Analytical Facility at Stellenbosch University (Stellenbosch, South Africa) by capillary electrophoresis using the Applied Biosystems (Foster City, USA) DNA Sequencer 3130xI. The precise lengths of the terminal fragments (TRFs) were determined according to the molecular weight standard ROX1.1 (with an acceptable error of $\pm 1 \mathrm{bp}$ ). Prior to fragment analysis, samples were denatured at $95^{\circ} \mathrm{C}$ for 5 minutes and stored on ice for 5 minutes; $4 \mu \mathrm{l}$, containing approximately $50 \mathrm{ng}$ of each digested product was mixed with the internal size standard and formamide, and analysed directly by capillary electrophoresis (50 cm capillary, POP7 polymer).

\subsubsection{Nitrogen-fixing bacterial community analysis using next generation sequencing (NGS)}

PolF (forward) and PolR (reverse) fusion primers (containing indexing adapter sequences $5^{\prime}$ TCG TCG GCA GCG TCA GAT GTG TAT AAG AGA CAG and 5' GTC TCG TGG GCT CGG AGA TGT GTA TAA GAG ACA G, respectively) were used to generate PCR amplicons. The PCR products were visualised on a $1 \%(\mathrm{w} / \mathrm{v})$ agarose gel. The appropriate bands were excised and purified using the NucleoSpin ${ }^{\circledR}$ gel and PCR clean up kit (Machery-Nagel) and sent to Inqaba Biotechnical Industries (Pretoria, South Africa) for NGS. PCR products were quantified, and library quality control was performed using an Agilent 2100 Bioanalyzer (Santa Clara, USA). Amplicons were indexed using the Nextera XT dual indexing kit (Illumina, San Diego, USA), and run on the Illumina MiSeq platform MCS version 2.5.0.5, according to the manufacturers' instructions. $20 \mathrm{Mb}$ of $2 \times 300$ base pairs paired end reads were produced for each amplicon. 


\subsection{Statistical and bioinformatics analyses}

\subsubsection{Analysis of physicochemical and culture-dependent nitrogen-fixing bacterial enumeration data}

The analysis of the experimental data was carried out using the software package $R$. Different one-way and higher dimensional ANOVA (Analysis of Variance) models were estimated including interactions between the factors. The estimated models were assessed by their significance and their meaning by the coefficient of determination. In addition, the Tukey Honest Significant Difference test was performed to identify pairwise differences between the means of the levels of factors (Yandell, 1997) and provide adjusted p-values for pairwise comparisons between different treatments.

\subsubsection{Analysis of terminal restriction fragment length polymorphism patterns}

T-RFLP patterns and quality were analysed using the freeware, PeakScanner ${ }^{\mathrm{TM}}$ (version 1.0) (Applied Biosystems, https://products.appliedbiosystems.com). The online software T-REX (http://trex.biohpc.org/) (Culman et al., 2009) was then used to create the data matrices as follows: Peak height was used to characterise each unique T-RF and only peaks greater than $30 \mathrm{bp}$ were considered to avoid primer-dimers and to obtain peaks within the linear range of the internal standard (Singh et al., 2006). The relative abundance of a T-RF in a T-RFLP profile was calculated by dividing the peak height of the T-RF by the sum of the peak heights (or fluorescence) of all the T-RFs in the profile. T-RFs with intensities lower than $0.5 \%$, which may have originated from background interference, were excluded from the matrices thereby minimizing the effect of the variations in the T-RFLP profiles caused by the starting quantities of DNA (Singh et al., 2006: Ding et al., 2013).

Data matrices obtained from T-REX were further analysed with the software Primer 6 (Primer-E Ltd, UK). The community structure data obtained by the T-RFLP data were squareroot transformed and a Bray-Curtis similarity matrix was generated to establish the cluster analysis (group average linkage) and non-metric multidimensional scaling (nMDS) plots. Two-way crossed Analysis of Similarity (ANOSIM) was used to test for significant differences in the NFB assemblages in the BSFs.

\subsubsection{Analysis of the next generation sequencing data}

The nifH amplicon sequences were processed to obtain high quality reads. The high quality reads were de-replicated and chimeric sequences were removed using USEARCH v6.0 (Edgar, 2011) in FunGene standalone pipeline (Fish et al., 2013). The nucleotide sequences were translated and trimmed to 60 amino acid length. Further, the peptide sequences were aligned using HMMER 3.0rc2 to the known nifH sequence database and operational taxonomic units (OTUs) were clustered based on the complete linkage clustering in Fungene. The taxonomy was assigned to each OTU clusters by extracting the representative 
nucleotide sequences and performing the NCBI-BlastX (with an E-value threshold of $\leq 1 \mathrm{e}-5$ ) homology search against NCBI Refseq database (downloaded on 3 November, 2016) (O'Leary et al., 2016). The singleton OTUs were removed and single rarefied to 3901 OTUs for the six samples which were assigned to taxonomy using MEGAN6 (Huson et al., 2016).

\section{Results}

\subsection{Analysis of the diazotrophic bacterial communities in surface and deep sites of biological sand filters}

The NFB communities in the BSFs were assessed using both T-RFLP fingerprinting and amplicon NGS of the nifH gene. The nMDS ordinations of the T-RFLP profiles (Fig. 1) clearly showed that there was a temporal community shift in the control system i.e. a succession not related to the addition of SWW, both at the surface and at depth. There was no difference in the treatment protocol of the control system for the duration of the study (6 months), and it has previously been shown that the bacterial communities in BSFs stabilise after 3 months (Ramond et al., 2012). It was therefore concluded that the shift was due to seasonal climatic changes as the systems were maintained in an undercover, outdoor environment. Secondly, the SWW had an impact of the NFB community structure, but only at the surface. The latter is clearly demonstrated in Fig. $1 \mathrm{~A}$, where points representing the baseline replicates of the NFB communities from the control and experimental systems cluster together. However, at the end of the study (final sampling instance), the points representing the replicates from both experimental BSFs $(1,2)$ group closely together, and are well separated from the control replicates. This was confirmed by 2-way crossed ANOSIM: surface replicates: baseline vs final: $R=0.643 / p=0.001$; surface replicates: SWW vs no SWW $R=0.457 / p=0.004$; deep replicates: baseline vs final: $R=0.822 / p=0.001$; deep replicates: SWW vs no SWW: $R=0.091 / p=0.233$. Lastly, there was a significant difference between the NFB community structures in the replicates from the surface and at depth in all BSFs. This was demonstrated by 2-way crossed ANOSIM which showed that, overall, the BSF communities from the surface and in-depth niches were significantly different $(R=0.728, p=0.001)$.

To further understand the impact of the SWW on the surface NFB communities, the replicate surface sand samples of each BSF were pooled to perform nifH amplicon NGS. Pooling was justified by the fact that on the ordination (Fig. 1A) the points representing the replicates were in close proximity, denoting similar NFB community structures. 


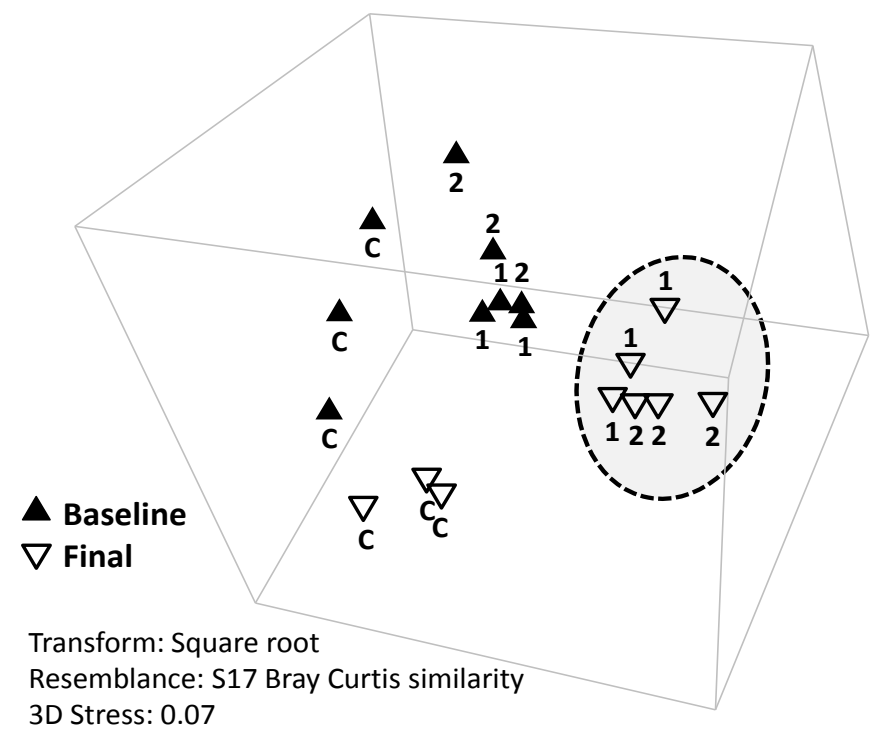

A

B

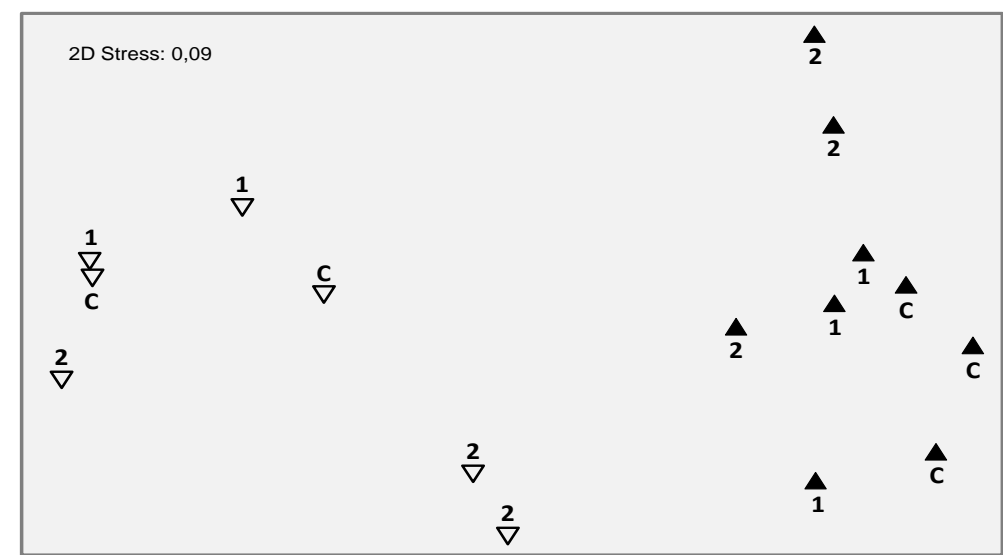

Fig. 1: nMDS plots showing the Bray-Curtis similarity of the nitrogen-fixing bacterial communities from the surface (A) and deep (B) replicate sand samples of the control (c) biological sand filter (baseline and final sampling instances) and the experimental systems $(1,2)$ before and after exposure to synthetic winery wastewater (baseline and final sampling instances). Please note that the 2D and 3D stress values are below 0.1 , indicating that the nMDS ordination accurately represents the samples relationships of the higherdimensional similarity matrix

At baseline, the NFB from each BSF were dominated by unclassified bacteria of the class Gammaproteobacteria. After exposure to SWW, the relative abundance decreased dramatically from $70.3 \%$ and $50.6 \%$ to $2.5 \%$ and $0.9 \%$ in the experimental BSFs 1 and 2, respectively. In contrast, the unclassified Gammaproteobacteria were still highly abundant (22.5\%) in the control BSF that had not been exposed to SWW (Fig. 2). Concomitantly, Deltaproteobacteria of the genus Geobacter increased to $18.5 \%$ and $15.4 \%$ in 1 and 2, respectively, but not in the control (2.1\%). Similarly, Alphaproteobacteria of the order Rhizobiales, which were not detected in any of the baseline samples, were selected by exposure to SWW $(11.5 \%$ and $9.2 \%$ in 1 and 2 , but not detected in the control in the 'final' samples) (Fig. 2). 


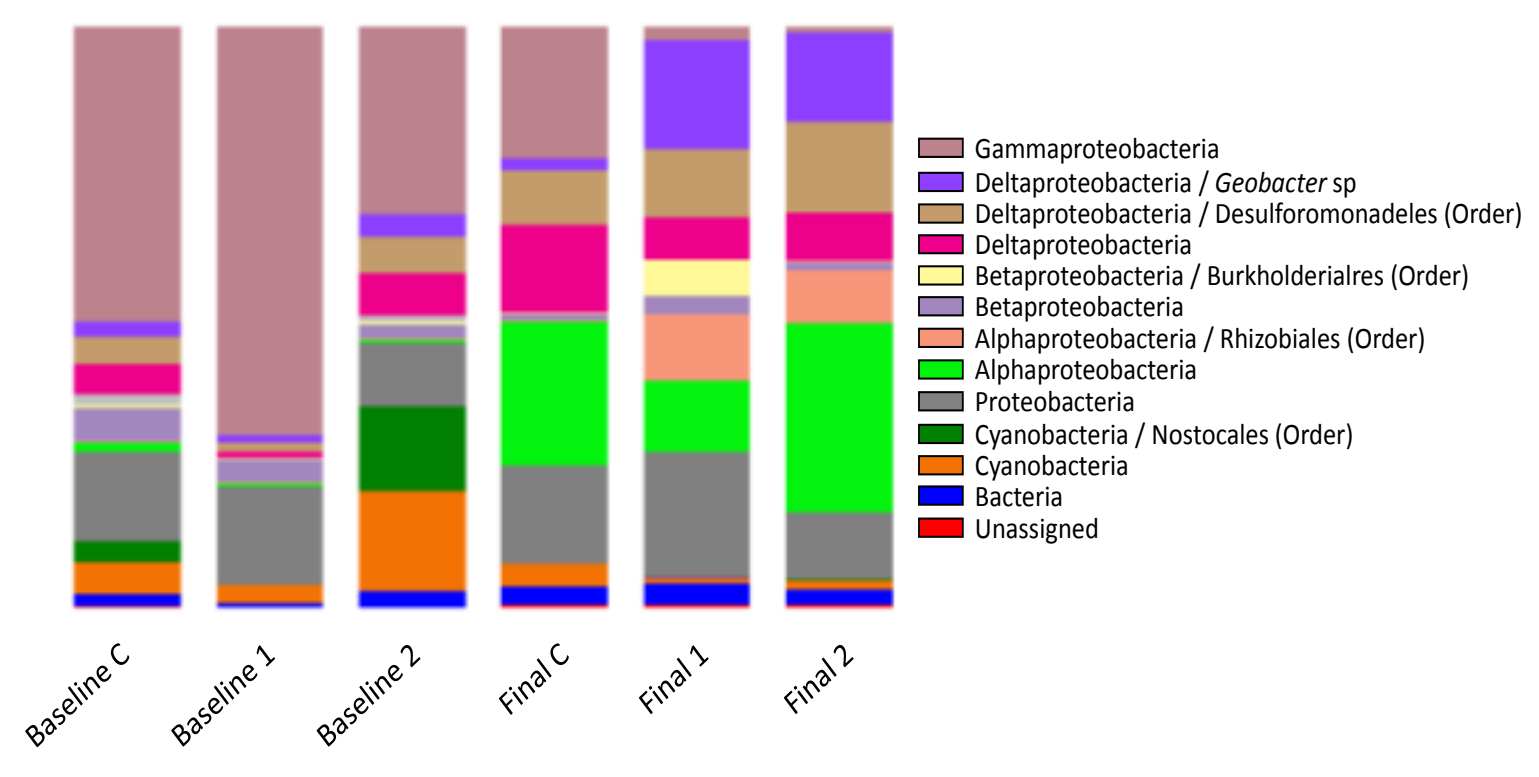

Fig 2: Bar chart depicting the relative abundance of nifH taxa, identified at the lowest taxonomic rank, within each surface diazotrophic community

\subsection{Quantification of nitrogen-fixing bacteria using culture-dependent techniques}

\subsubsection{Temporal changes in the number of nitrogen-fixing bacteria in the superficial sites of biological sand filters}

Colony counts from sand sample replicates were assumed to represent the biofilmassociated bacterial populations, while those from pore water sample replicates were assumed to represent the planktonic populations. Temporal changes were determined by comparing results from samples taken at baseline, to those taken at the final sampling instance. It is acknowledged that the results obtained from NDMSA may have over- or under-estimated the number of NFB. Non-NFB may have been able to grow utilising $N$ supplied by the NFB colonies. Conversely, some NFB may have been unable to grow on the NDMSA under the given culture conditions. In the case of the Azotobacter spp., a selective media was used. The colonies were all highly mucoid cream or brown-pigmented colonies typical of Azotobacter spp. Gram stains were performed on selected colonies, which in all instances revealed large encapsulated Gram negative coccobacilli in pairs, also typical of members of this genus.

Biofilm-associated communities: There was a significant temporal increase in the number of colonies grown on NDMSA agar from replicates taken from the experimental BSFs $(p<$ $0.01 ; r^{2}=0.90$; Fig. $\left.3 A\right)$, but not from the control $(p>0.5)$. There was also a $>2$ log increase in the number of colonies from the replicates from the control and experimental systems grown on Azotobacter medium (Fig. 3B). As there was a significant increase in the replicates from all systems, the increase in the experimental replicates was not significant when compared with the control $(p>0.5)$. 
Planktonic communities: In contrast to the biofilm-associated communities, there was no significant difference in the number of colonies grown on NDMSA agar from any of the replicate samples (control/experimental; baseline/final) (Fig. $3 \mathrm{C}$ ), but there was a significant temporal increase in the number of colonies grown on Azotobacter medium in the experimental systems when compared to the replicate samples (i) taken at baseline $(p<$ $\left.0.01 ; r^{2}=0.86\right)$, and (ii) from the control at the final sampling instance $\left(p<0.01 ; r^{2}=0.83\right)$.

\subsubsection{Temporal changes in the number of nitrogen-fixing bacteria in the deep sites of biological sand filters}

The number of colonies grown on NDMSA and Azotobacter medium from replicate samples taken from deep sites (Fig. $3 E$ to $3 H$ ) were significantly lower $(p<0.01)$ than the superficial sample counterparts (Fig. 3A to 3D).

Biofilm-associated and planktonic communities: There were no significant differences in the number of colonies grown on NDMSA medium from any of the replicate samples $(p<$ $0.5 ; r^{2}=0.70$ to 0.90$)$. Notable temporal increases in colony counts on Azotobacter medium were seen in all systems, including the control, but there were no significant differences from any of the replicate samples taken at either the baseline $\left(p<0.5 ; r^{2}=0.94\right)$ or final $(P<$ $\left.0.5 ; r^{2}=0.86\right)$ sampling instances. Similar results were found with the planktonic communities on Azotobacter medium, but the results from the NDMSA medium were excluded because overgrowth of swarming species did not allow enumeration of 'final' results from BSF 1 (Fig $3 \mathrm{G}, \mathrm{H}$ ). 


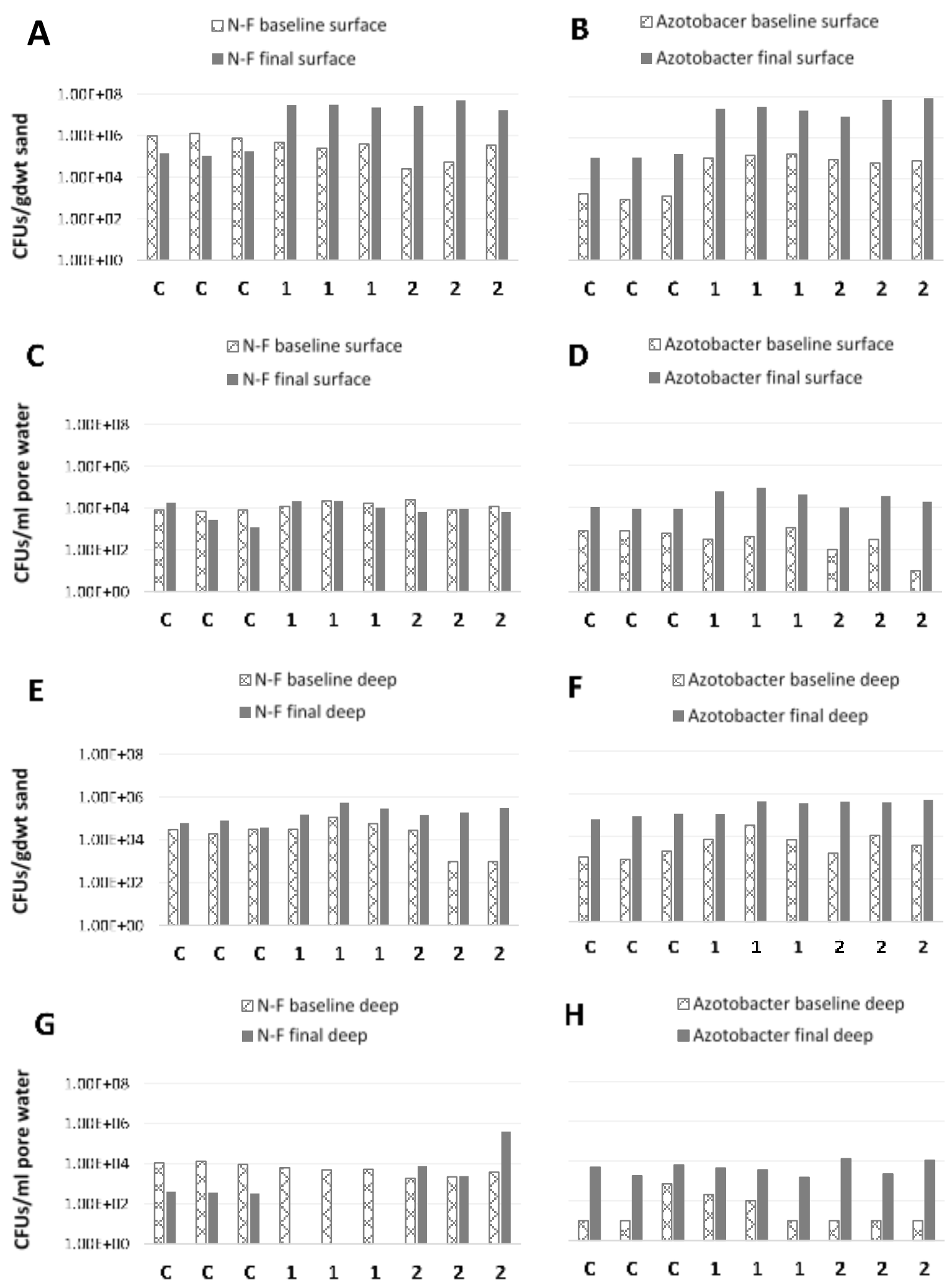

Fig 3: Colony counts performed on superficial and deep pore water and sand sample replicates taken from the BSFs on media selective for NFB (N-F) and Azotobacter spp. (Azotobacter). Superficial sites = A to D, Deep sites $=\mathrm{E}$ to $\mathrm{G}$. Note: logarithmic scale used in A to G. gdwt = gram dry weight, CFUs = colony forming units. 


\subsection{Chemical parameters measured in pore water and effluent samples}

\subsubsection{Chemical oxygen demand concentrations}

There were no significant differences $(p>0.05)$ in the COD concentrations $[39 \pm 19$ $\mathrm{mgCOD} / \mathrm{L}$; range: $17-90 \mathrm{mgCOD} / \mathrm{L}$ ) in any of the replicate pore water samples taken (i) at baseline, (ii) from the superficial and deep sites of the control at the final sampling instance, and (iii) from the deep sites of the experimental systems at the final sampling instance $(n=$ 29). There was a significant difference [*** significance $(p<0.001), r^{2}=0.89$ ] in the COD concentrations of all of these samples [described in ( $\mathrm{i}$ to iii)] and those taken from the superficial sites of the experimental systems [335 $\pm 60 \mathrm{mgCOD} / \mathrm{L}$; range 288-423 $\mathrm{mgCOD} / \mathrm{L}$; $n=6]$ at the final sampling instance (Fig. 4).

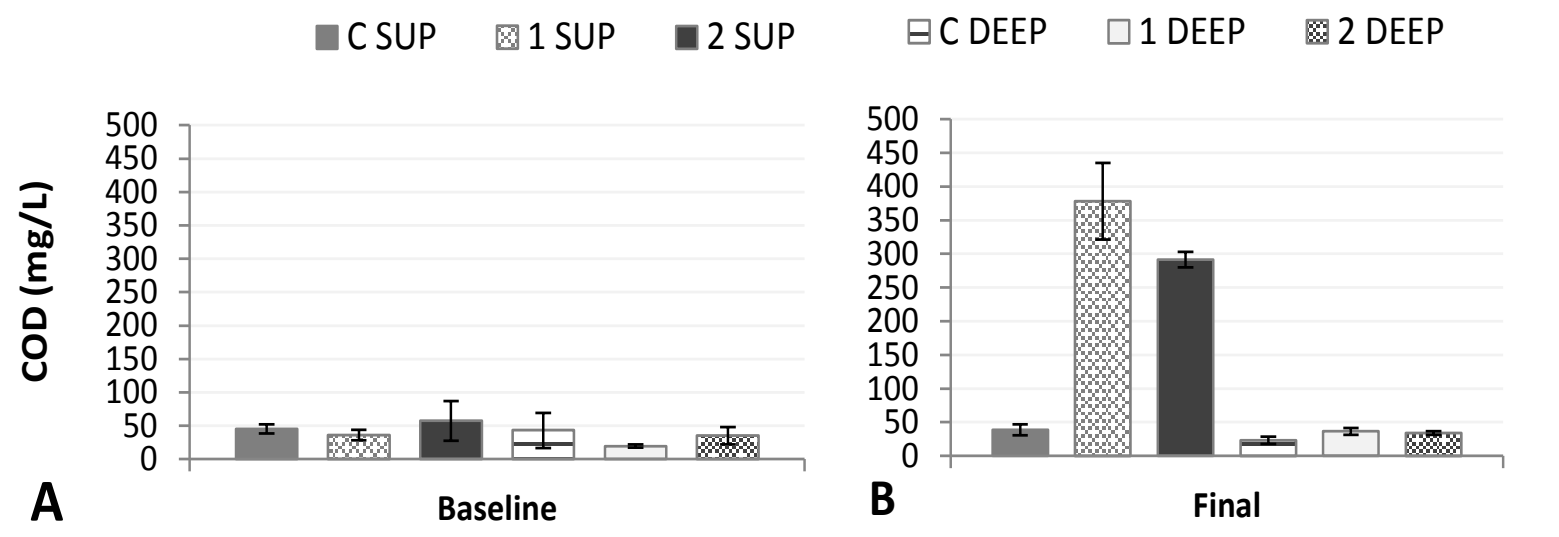

Fig 4: Concentrations of chemical oxygen demand in pore water samples taken at baseline (A) and final (B) sampling instances

The effluent baseline COD concentrations from each of the BSFs, as well as those from the control ranged from 16 to $23 \mathrm{mg} / \mathrm{L}$. The monthly effluent COD concentrations from samples taken from the experimental systems after amendment with SWW showed a temporal decrease, with removal performances of $84 \%, 86 \%$ and $89 \%$ for BSF1 and $86 \%, 87 \%$ and $89 \%$ for BSF2 for month 1, 2 and 3, respectively.

\subsubsection{Nitrogen speciation profiles}

Ammonia levels were below the detection limit of the assay in all replicate samples, and nitrite concentrations were negligible (range 0.01 to $0.34 \mathrm{mg} / \mathrm{L}$ ). Nitrate was the largest contributor to total nitrogen (Fig. 5). There were no statistical differences in the nitrate or nitrite concentrations: (i) in any of the baseline samples (control and experimental systems /superficial and deep sites), (ii) in the final samples taken from the deep sites (control and experimental systems), (iii) in the final samples taken from the superficial sites of the experimental systems, and (iv) in the baseline and final samples from the deep sites of the 
experimental systems $(p>0.05)$. However, there were significant differences in the nitrate and nitrite concentrations (i) in the final samples taken from the control and experimental systems from the superficial sites and (ii) in the final samples taken from the control systems from the superficial and deep sites [nitrate $* * *$ significance $(p<0.001)$, nitrite **significance $\left.\left.(0.001>p<0.01) ; r^{2}=0.95\right)\right]$.
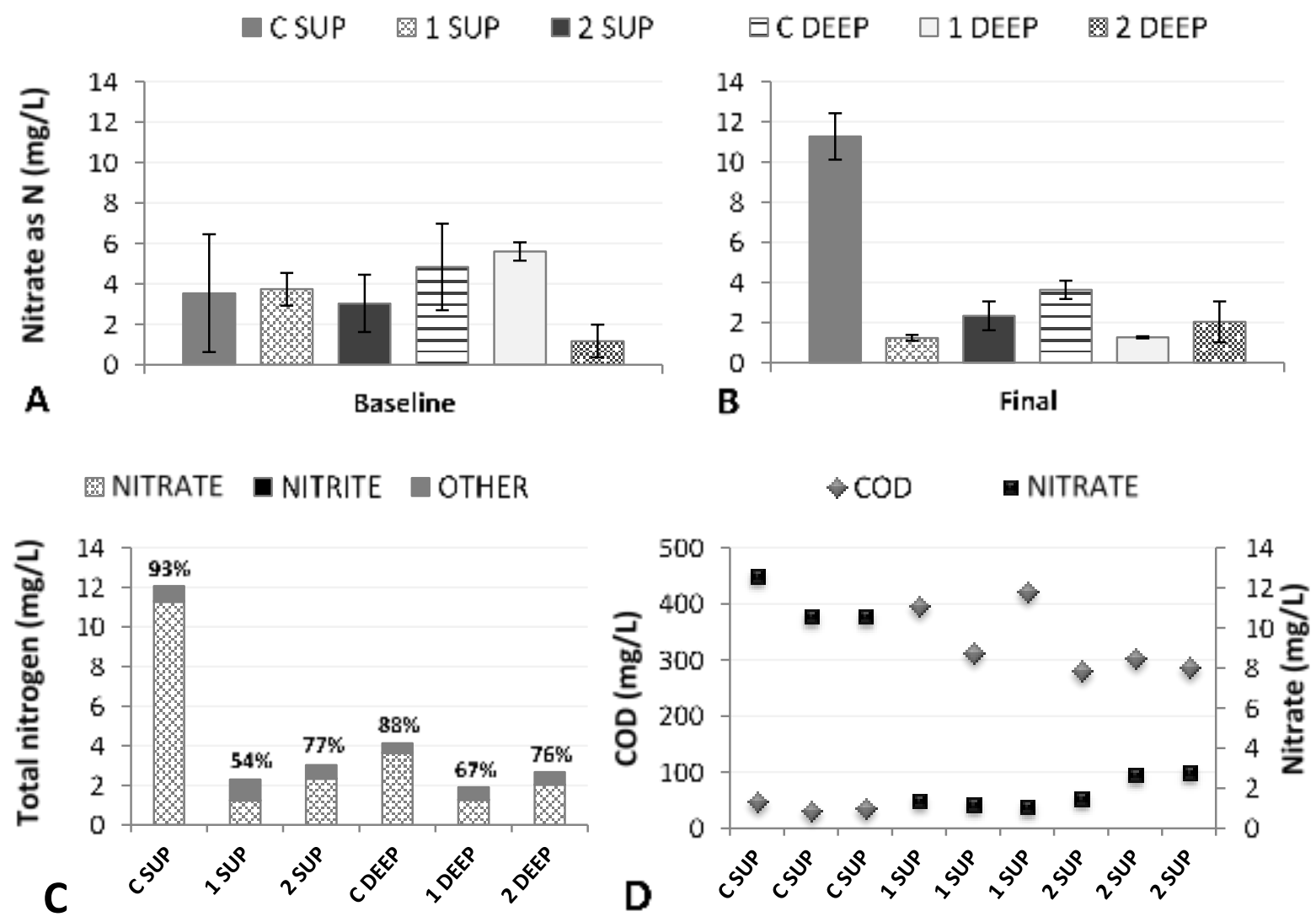

Fig. 5: Comparison of the average nitrate concentrations in the baseline replicate samples taken from the superficial and deep sites of control and experimental systems at baseline (A) and final (B) sampling instances; Average percentage of nitrate to total nitrogen in the replicate samples taken from the BSF niches at the final sampling instance (C), and comparison between average chemical oxygen demand and nitrate concentrations in replicate samples taken at the final sampling instance (D) SUP = superficial

\subsubsection{Correlation between chemical oxygen demand (COD) and nitrogen species}

There was no significant correlation between COD and nitrate concentrations $(p>0.05 ; 95 \%$ confidence) in the pore water replicates taken at baseline. There was a significant inverse correlation between COD and nitrate in the replicates from the control and experimental systems taken at the final sampling instance at the superficial sites [*** significance $(p<$ $0.001) ; r=-0.96 ; 95 \%$ confidence; Fig 6 ] and the deep sites [ ${ }^{* *}$ significance $(0.001>p<0.01)$; $r=-0.79 ; 95 \%$ confidence]. 


\section{Discussion}

\subsection{Qualitative and quantitative changes in the nitrogen fixing bacterial communities in response to exposure to high carbon to nitrogen ratio wastewater}

The NFB communities in the control BSF experienced a temporal (seasonal) shift not related to exposure to SWW (Fig. 1, Fig. 2). By comparing the results obtained from the experimental sample replicates with those of the control, molecular studies showed that the high C:N SWW exerted selective pressure on the NFB population at the surface of the BSFs, but not at depth. Results of culture-dependent studies showed that both planktonic and biofilm-associated NFB also only increased in number at the surface of BSFs treating high C:N wastewater. It is postulated that this was mainly due to higher availability of atmospheric nitrogen at the surface.

While the majority of environmental bacteria cannot be cultured, rare species may be overlooked when culture-dependent techniques are not employed (Stefani et al., 2015). Presumptive Azotobacter spp. were cultured in high numbers (Fig. 3) as well as being visualised as dominant morphotypes in pore water samples using classical microscopy (Gram stain). Azotobacter spp. are ubiquitous obligate aerobes that are important in agriculture because of their ability to fix nitrogen at high rates (Özen and Ussery, 2012). They belong to the family Pseudomonadaceae, the order Pseudomonadales and the class Gammaproteobacteria. In this study, we analysed nifH sequences to the lowest taxonomic rank possible. Consequently, only some $\mathrm{N}$-fixing nifH populations could be identified from the Domain Bacteria down to the genus level (Geobacter spp.) (Fig. 2).

NGS sequencing revealed a dramatic temporal decrease in the relative abundance of NFB of the class Gammaproteobacteria at the surface of all the BSFs, especially in the experimental systems. This may seem counter-intuitive, but it is impossible to speculate on what fraction of the class was represented by Azotobacter spp.

What is noteworthy from the NGS results is that the SWW was selective for the genus Geobacter and order Rhizobiales, confirming previous findings that organic-rich effluents select specific $\mathrm{N}$-fixing community members in BSFs (Ramond et al., 2013). For efficient organic bioremediation in BSFs, the selected BSF microbial community must be able to both effectively degrade the 'contaminants' and counterbalance the high C:N ratio of the wastewater by fixing atmospheric N (Ramond et al., 2013). Members of the Geobacter genus and the Rhizobiales order (e.g. the free-living Agrobacterium, Rhizobium, Sinorhizobium and Bradyrhizobium genera) are well known for their ability to degrade aromatic compounds (Zhang et al., 2014; Teng et al., 2015). Fe(III)-reducers such as Geobacter spp. have also long been recognized as key-players in subsurface/anoxic biodegradation of organics in contaminated environments, and their bioremediatory capacity can be stimulated by the addition of bioavailable Fe(III) (Lovley, 1995). These 
results further support previous studies using the nifH gene as a marker, where Geobacter and/or Rhizobiales were found in diverse environments including rice roots (Ferrando and Scavino, 2015), an Alpine glacier (Duc et al., 2009), and a high altitude lake (Villa-Costa et al., 2014).

Another noteworthy finding was that the numbers of culture-able NFB were significantly higher $(p<0.01)$ in the sand samples (CFUs/ml pore water) when compared to the pore water samples (CFUs/gdwt sand). Although the units of expression are not the same, the density of the sand is known $(1.6 \mathrm{~g} / \mathrm{ml})$, allowing a rough comparison to be made. The results strongly suggest that the NFB proliferated preferentially in a biofilm environment in the BSFs. It is also possible that a proportion of the fraction classed as planktonic in this study may have sloughed off from the biofilm to some degree during sample extraction. These results are important from a wastewater treatment perspective because the presence of free-living microoganisms in treated effluent leads to turbidity and increased COD concentrations (Olofsson et al., 1998). This in turn translates into decreased system performance.

It is recognised that culture-independent methods are crucial for ecological studies and many microorganisms cannot be cultured. However, in this study, the selection of Azotobacter spp. in response to the presence of high C:N wastewater would have been overlooked if samples were not cultured. This is probably related to the fact that the nifH primers used to barcode the BSF diazotrophic communities do not enable access to the full nifH diversity (Gaby and Buckley, 2012).

\subsection{Assessment of nitrogen and chemical oxygen demand in biological sand filters treating high carbon to nitrogen ratio wastewater}

It has previously been established that BSFs treating SWW perform well in terms of COD removal, that organic molecules (including phenolics) are degraded preferentially in the deep layers (Slade et al., 2003; Welz et al., 2014a, 2014b), and that >90\% COD removal can be achieved when treating high C:N wastewater (ethanol) with a COD of $>26000 \mathrm{mg} / \mathrm{L}$ (Welz et al., 2011). In this study, COD removal in the experimental BSFs reached $89 \%$ by the end of the SWW amendment period, which is in line with previous findings. Therefore, overall system performance was not evaluated further, but nitrogen and nitrogen-COD interactions in the surface and deep niches of the BSF, and how these may relate to the NFB population, were briefly assessed.

In the environment, $\mathrm{N}$ is always in a state of flux, and will only accumulate in soil when $\mathrm{N}$ fixation occurs at a higher rate than uptake by plants and microbial denitrification (Knorr et al., 2015). For complete nitrogen removal in conventional wastewater treatment systems, all ammonia should be nitrified. Thereafter, sufficient carbon electron donors need to be available, accompanied by low dissolved oxygen (DO) concentrations to achieve high rates 
of denitrification via the classical heterotrophic pathway (Wang et al., 2016). In the case of the experimental BSFs treating SWW, there was an abundance of (carbonaceous) electron donors for denitrification. No exogenous electron donors are required if the Annamox pathway for denitrification is followed (Wang et al., 2016).

To assess whether there were any temporal differences in the nitrogen profiles from the control and experimental replicates, the nitrite, nitrate and ammonia concentrations were determined in the pore water samples. Nitrate was the major contributor to total nitrogen (Fig. 5). Despite a three month equilibration period before the start of the experiment, there was a significant accumulation of nitrate at the surface of the control BSF system, but not in the experimental systems. As negligible amounts of $\mathrm{N}$ were added to the system, the nitrate accumulation was assumed to result from $\mathrm{N}$-fixation followed by nitrification at the surface.

Many species of photosynthetic bacteria fix nitrogen at high rates (Nayak et al., 2004). It is postulated that these may have contributed low levels of $\mathrm{N}$ at the surface of the BSFs, because in this study, as well as previous studies, green crusts grew randomly only on the surface of BSFs that had not been exposed to SWW (controls). It was assumed that SWW was toxic to these microbial species, or that photosynthetic species could not compete with functional heterotrophic species in the presence of SWW. This is supported by the fact that green crusts did not grow in the experimental replicates. Furthermore, it is likely that exposure of the surface layers to atmospheric oxygen, and lack of electron donors for denitrification led to accumulation of nitrate at the surface, but not in the deep niches of the control BSF.

In contrast to the control, the nitrate concentrations in both the deep and surface layers of the experimental BSFs did not differ significantly from the baseline to the final sampling instance (Fig. 5). In terms of the classical denitrification pathway, ideal conditions existed in the experimental systems to denitrify $\mathrm{N}$ which may have been added via atmospheric fixation. Firstly, there was an abundance of carbonaceous electron donors, and secondly, heterotrophic biodegradation of organics preferentially utilises oxygen as the terminal electron acceptor, creating anoxic conditions conducive to denitrification.

\section{Conclusions and recommendations}

In conjunction with previous studies, the results of this study confirms that NFB communities in BSFs adapt to the presence of high $\mathrm{C}: \mathrm{N}$ wastewater such as winery effluent. Similar to suspended growth systems treating kraft and paper mill effluent, increased nitrogen fixation can enhance performance in systems that are nutrient limited. If this phenomenon is widespread, it may obviate the need for nutrient addition in many systems treating high $\mathrm{C}: \mathrm{N}$ wastewater. Further research on different wastewater streams and systems is needed. The effect of operational parameters on nitrogen fixation may be important, especially in systems with short hydraulic retention times. 


\section{Acknowledgements}

The authors would like to acknowledge the Cape Peninsula University of Technology for funding this project.

\section{References}

Aquilanti L, Taccari M, Bruglieri D, Osimani A, Clementi F, Comitini F, Ciani M. 2014. Integrated biological approaches for olive mill wastewater treatment and agricultural exploitation. Int. Biodeterior. Biodegr. 88, 162-168.

Balis C, Chatzipavlidies J, Flouri F. 1996. Olive mill waste as a substrate for nitrogen fixation. Int. Biodeter. Biodegr. 38, 139-178.

Barua S, Tripathi S, Chakraborty A, Ghosh S, Chakrabarti K. 2012. Characterization and crop production efficiency of diazotrophic bacterial isolates from coastal saline soils. Microbiol. Res. 167, 95-102.

Brown ME, Burlingham SK, Jackson RM. 1962. Studies on Azotobater species in soil. I. Comparison of media and techniques for counting Azotobacter in soil. Plant Soil 17, 309319.

Chronopolou P-M, Fahy A, Coulon F, Païssé S, Goňi-Urriza M, Peperzak L, Acuňa Alvarez L, Mckew BA, Lawson T, Timmis KN, Duran R, Underwood GJC, McGenity TJ. 2013. Impact of a simulated oil spill on benthic phototrophs and nitrogen-fixing bacteria in mudflat mesocosms. Environ. Microbiol. 15, 242-252.

Clark TA, Dare PH, Bruce ME. 1997. Nitrogen fixation in an aerated stabilization basin treating bleached kraft mill wastewater. Water Environ. Res. 69, 1039-1046.

Culman SW, Bukowski R, Gauch HG, Cadillo-Quiroz H, Buckley DH. 2009. T-REX: Software for the processing and analysis of T-RFLP data. BMC Bioinformatics 10, 171.

De Salamone IEG, Funes JM, Di Salve LP, Escobar-Ortega JS, D'Auria F, Ferrando L, Fernandez-Scavino A. 2012. Inoculation of paddy rice with Azospirillum brasilense and Pseudomonas fluorescens: Impact of plant genotypes on rhizosphere microbial communities and field crop production. Appl. Soil Ecol. 61, 196-204.

Dennis MA, Cotter ML, Slade AH, Gapes DJ. 2004. The performance of a nitrogen-fixing SBR. Water Sci. Technol. 50, 269-278.

Ding T, Palmer MW, Melcher U. 2013. Community terminal restriction fragment length polymorphisms reveal insights into the diversity and dynamics of leaf endophytic bacteria. Biomed Central Microbiol. 13, 1-11. 
Duc L, Noll M, Meier BE, Burgman H, Zeyer J. 2009. High diversity of diazotrophs in the forefield of a receding Alpine glacier. Microbial Ecol. 57, 179-190.

Edgar RC, Haas BJ, Clemente JC, Quince C, Knight R 2011. UCHIME improves sensitivity and speed of chimera detection. Bioinformatics 27, 2194-2200.

Ferrando L, Scavino AF. 2015. Strong shift in the diazotrophic endophytic bacterial community inhabiting rice (Oryza sativa) plants after flooding. Microbial Ecol. 91, 1-12.

Fish JA, Chai B, Wang Q, Sun Y, Brown CT, Tiedje JM. 2013. FunGene: the functional gene pipeline and repository. Front. Microbiol. 4, 291.

Gaby JC, Buckley DH. 1012. A comprehensive evaluation of PCR primers to amplify the nifH gene of nitrogenase. PLoS One 7, 1-12.

Gauthier F, Neufeld JD, Driscoll BT, Archibald FS. 2000. Coliform bacteria and nitrogen fixation in paper and pulp mill effluent treatment systems. Appl. Environ. Microb. 66, 51555160.

Gentry TJ, Rensing C, Pepper JL. 2004. New approaches for bioaugmentation as a remediation technology. Crit. Rev. Env. Sci. Tec. 34, 447-494.

Huson D H, Beier S, Flade I, Górska A, El-Hadidi M, Mitra, S, Tappu, R. 2016. MEGAN community edition-interactive exploration and analysis of large-scale microbiome sequencing data. PLoS Comput. Biol. 12, e1004957.

Kargi F, Özmıhçı S. 2004. Batch biological treatment of nitrogen deficient synthetic wastewater using Azotobacter supplemented activated sludge. Bioresource Technol. 94, 113-117.

Knorr K-H, Horn MA, Borken W. 2015. Significant nonsymbiotic nitrogen fixation in Patagonian ombotrophic bogs. Glob. Change Biol. 21, 2357-2365.

Knowles P, Dotro G, Nivala J, Garcia J. 2010. Clogging in subsurface flow treatment wetlands: occurrence and contributing factors. Ecol. Eng. 37, 99-112.

Knowles R, Neufeld R, Simpson S. 1974. Acetylene reductase (nitrogen fixation) by paper and pulp mill effluent and by Klebsiella isolated from effluent and environmental situations. Appl. Microbiol. 28, 603-613.

Lovley DR. 1995. Bioremediation of organic and metal contaminants with dissimilatory metal reduction. J. Indust. Microbiol. Biotechnol. 14, 85-93.

Malandra, L., Wolfaardt, G., Zietsman, A., Viljoen-Bloom, M., 2003. Microbiology of a biological contactor for winery wastewater treatment. Water Res. 37, 4125-4134. 
Nayak S, Prasana R, Pabby A, Dominic TK, Singh PK. 2004. Effect of urea, blue-green algae and Azolla on nitrogen fixation and chlorophyll accumulation in soil under rice. Biol. Fert. Soils 40, 67-72.

O'Leary NA, Wright MW, Brister JR, Ciufo S, Haddad D, McVeigh R et al (2016). Reference sequence (RefSeq) database at NCBI: current status, taxonomic expansion, and functional annotation. Nucleic Acids Res. 44, D733-745.

Olivares J, Bedmar EJ, Sanjuán J. 2013. Biological nitrogen fixation in the context of global change. Mol. Plant Microbe In. 26, 486-494.

Olofsson A-C, Zita A., Hermansson M. 1998. Floc stability and adhesion of green-fluorescentprotein-marked bacteria to flocs in activated sludge. Microbiology 144, 519-528.

Özen Al, Ussery DW. 2012. Defining the Pseudomonas genus: where do we draw the line with Azotobacter. Microbial Ecol. 63, 239-248.

Piperidou Cl, Chaidou Cl, Stalikas CD, Soulti K, Pilidis GA, Balis C. 2000. Bioremediation of olive oil mill wastewater: chemical alterations induced by Azotobater vinelandii. J. Agr. Food Chem. 48, 1941-1948.

Poly F, Jocteur-Monrozier R, Bally R. 2001. Improvement in the RFLP procedure for studying the diversity of the nifH gene in communities of nitrogen fixers in soil. Res. Microbiol. 152, 95-103.

Pratt S, Tan, M, Gapes D, Shilton A. 2007. Development and examination of a granular nitrogen-fixing wastewater treatment system. Process Biochem. 42, 863-872.

Ramond J-B, Welz PJ, Cowan DA, Burton SG. 2012. Microbial community structure stability, a key parameter in monitoring the development of constructed wetland mesocosms during start-up. Res. Microbiol. 163, 28-35.

Ramond, J-B., Welz, P.J., Tuffin, M.I., Burton, S.G., Cowan, D.A. 2013 Selection of diazotrophic bacterial communities in biological sand filter mesocosms used for the treatment of phenolic-laden wastewater. Microbial Ecol. 66, 563-570.

Ray R, Majumber N, Das S, Chowdhury C, Jana TK. 2014. Biogeochemical cycling of nitrogen in a tropical mangrove ecosystem, east coast of India. Mar. Chem. 167, 33-43.

Rennie RJ. 1981. A single medium for the isolation of acetylene-reducing (dinitrogen-fixing) bacteria from soils. Can. J. Microbiol. 27, 8-14.

Rodriguez-Caballaro A, Ramond J-B., Welz PJ, Cowan DA., Odlare M, Burton SG. 2012. Treatment of high ethanol concentration wastewater by biological sand filters: Enhanced COD removal and bacterial community dynamics. J. Environ. Manage. 109, 54-60. 
Sakar J, Kazy SK, Gupta A, Dutta A, Mohapatra B, Roy A, Bera P, Mitra A, Sar P. 2016. Biostimulation of indigenous microbial community for bioremediation of petroleum refinery sludge. Front. Microbiol. 7, 1407.

Schank CS, Koehnle TJ. 2009. Pseudoreplication is a pseudoproblem. J. Comp. Psychol. 123, 421-433.

Singh BK, Nazaries L, Munro S, Anderson IC, Campbell CD. 2006. Use of multiplex terminal restriction length polymorphism for rapid and simultaneous analysis of different components of the soil microbial community. Appl. Environ. Microb. 72, 7278-7285.

Slade AH, Anderson SM, Evans BG. 2003. Nitrogen fixation in the activated sludge treatment of thermomechanical pulping wastewater: effect of dissolved oxygen. Water Sci. Technol. 8, $1-8$.

Stefani OP, Bell TH, Marchand C, de la Providencia E, Yassimi AE, St-Arnaud M, Hijri M. 2015. Culture-dependent and -independent methods capture different microbial community fractions in hydrocarbon contaminated soils. PLoS One DOI:10.1371/journal.pone.0128272: 1-16.

Tchobanoglous G, Burton FL, Stensel HD, Metcalf \& Eddy. 2003. Wastewater engineering: Treatment and reuse. Boston: McGraw-Hill.

Teng Y, Wang X, Li L, Li Z, Luo Y. 2015. Rhizobia and their bio-partners as novel drivers for functional remediation in contaminated soils. Front. Plant Sci. 6.

Vila-Costa M, Bartrons M, Catalan J, Casamayor EO. 2014. Nitrogen-Cycling Genes in Epilithic Biofilms of Oligotrophic High-Altitude Lakes (Central Pyrenees, Spain). Microbial Ecol. 68, 60-69.

Wang B, Peng Y, Guo Y, Zhao M, Wang S. 2016. Nitrogen removal from wastewater and external waste activated sludge utilisation/reduction by simultaneous sludge fermentation, denitrification and anammox (SFDA). Bioresource Technol. 214, 284-291.

Welz PJ, Le Roes-Hill M. 2014b. Biodegradation of organics and accumulation of metabolites in experimental biological sand filters used for the treatment of synthetic winery wastewater: a mesocosm study. J. Water Proc. Eng. 3C, 155-163.

Welz PJ, Palmer Z, Isaacs S, Kirby B, Le Roes-Hill M. 2014a. Analysis of substrate degradation, metabolite formation and microbial community responses in sand bioreactors treating winery wastewater: a comparative study. J. Environ. Manage. 145, 147-156.

Welz PJ, Ramond JB, Cowan DA, Prins A, Burton SG. 2011. Ethanol degradation and the value of incremental priming in pilot scale constructed wetlands. Ecol. Eng. 37, 1453-1459. 
Welz, P.J. Holtman G.A., Haldenwang, R., Le Roes-Hill, M. 2016. Characterisation of winery wastewater from continuous-flow settling basins and waste stabilisation ponds over the course of one year: implications for biological wastewater treatment and land application. Water Sci. Technol. 74: 2036-204

Wong PY, Cheng KY, Kakronen AH, Sutton DC, Ginige MP. 2014. Enrichment of anodophilic nitrogen fixing bacteria in a bioelectrochemical system. Water Res. 64, 73-81.

Yandell BS, 1997 Practical Data Analysis for Designed Experiments. Chapman and Hall, Boca Raton, USA.

Zhang T, Tremblay PL, Chaurasia AK, Smith JA, Bain TS, Lovley DR. 2014. Identification of genes specifically required for the anaerobic metabolism of benzene in Geobacter metallireducens. Front. Microbiol. 5, 245-252.

Zuberer DA in Weaver J, Angle, JS, Bottomly PS. Methods of Soil Analysis. Part 2 Microbiological and Chemical properties. Soil Science Society of America Book Series 5, Wisconson, USA. 


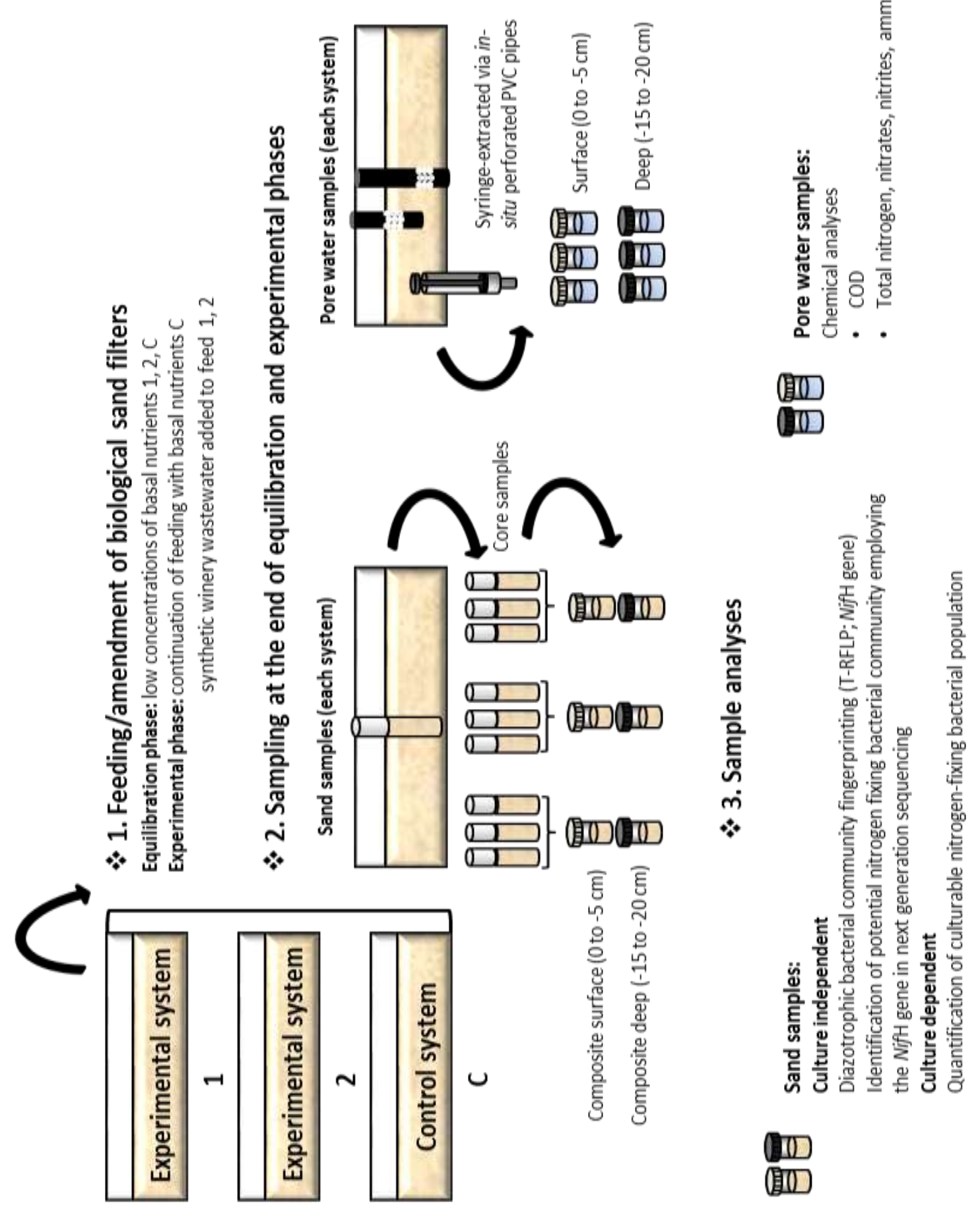

